\title{
Sobre a necessidade de um diálogo intercultural concretizador dos direitos humanos
}

\author{
On the need for an intercultural dialogue \\ that concretizes human rights
}

Edna Raquel Hogemann ${ }^{1}$

Vinicius Figueiredo Chaves $^{2}$

\section{RESUMO}

O estabelecimento de um corpus de direitos humanos, edificado no respeito cultural, não se revela algo impossível. A existência de valores que são comuns a todas as culturas, tais como o respeito à vida, e à liberdade, entre outros demonstram essa possibilidade. Necessário se faz promover o diálogo intercultural, embases possíveis, sem a imposição pontos de vista predefinidos. Nesse sentido, o presente ensaio, tendo por referencial as contribuições de Cornelius Castoriadis, AbdullahiAn-Na'im e Boaventura de Sousa Santos, aponta para alguns elementos relevantes dessa discussão, tais como a noção de autonomia tanto individual como coletiva na construção do direito e das instituições sociais, a busca de uma metodologia apta a possibilitar a concretização desse diálogo entre as diversas culturas que leve em conta as questões políticas existentes e os paradoxais olhares que ora tendem ao multiculturalismo ou ao universalismo. O ensaio não se pretende uma resposta definitiva ao complexo tema, mas tão somente um contributo à discussão que segue sendo urgente e necessária.

Palavras-chave: Direitos Humanos; concretização; autonomia política; diálogo intercultural; universalismo; multiculturalismo

\begin{abstract}
${ }^{1}$ Pós-doutora em Direito-UNESA/RJ, doutora em Direito-UGF/RJ.

${ }^{2}$ Doutor em Direito- UNESA/RJ
\end{abstract}

The establishment of a corpus of human rights, built on cultural respect, does not prove to be impossible. The existence of values that are common to all cultures, such as respect for life, and freedom, among others, demonstrate this possibility. It is necessary to promote intercultural dialogue, on a possible basis, without imposing predefined views. In this sense, this paper, with reference to the contributions of Cornelius Castoriadis, Abdullahi An-Na'im and Boaventura de Sousa Santos, points to some 
important elements of this discussion, such as the notion of autonomy both individual and collective in building the right and social institutions, the search for a suitable methodology to permit the implementation of the dialogue between cultures that takes into account the political and looks paradoxical that now tend to multiculturalism or universalism. The essay is not intended to be a definitive answer to the complex theme, but only a contribution to the discussion that remains urgent and necessary.

Key-words: Human Rights; concretization; political autonomy; intercultural dialogue; universalism; multiculturalism

\section{Introdução}

Os direitos humanos na tradição tanto filosófica como jurídica no âmbito do pensamento ocidental distinguem-se como um conjunto de direitos que almejam ter um status de universalidade. Essa qualidade, no entanto, implica necessariamente que para a sua integral realização haja a compreensão segundo a qual o universal possa vira se realizar pelas mais diversas formas e manifestações. Em outras palavras, isso significa de acolher-se a ideia segundo a qual

a própria complexidade da universalidade possa conduzir os seres humanos ao encontro de novas formas de expressão do mesmo conceito e dos mesmos valores como se encontram, ainda que formalmente, fulcrados na tradição ocidental.

Diversos autores têm-se voltado para essa intrigante e desafiadora tarefa em como manejar os instrumentos que possibilitem contemplar inclusivamente a construção de uma sociedade democrática de direito, no quadro do pluralismo cultural da contemporaneidade.

Todas as contribuições que estejam voltadas à consagração da pessoa humana e ao respeito de seus direitos inalienáveis, como são dos direitos humanos e que possam permitir que se tenha uma visão mais universal do homem e da sociedade, visão esta que se alforrie da "camisa de força" das díspares formas de universalismo e relativismo cultural existentes e que assinalam sobre maneira o pensamento filosófico e político da contemporaneidade. O presente ensaio, ao apresentar, ainda que de modo breve o pensamento de autores como Castoriadis, An-Na'im e Sousa Santos,oferece,em alguma maneira, elementos instrumentais como um contributo a esse debate que se revela tanto atual quanto necessário. 


\section{Cornelius Castoriadis e a relação da sociedade autônoma com os direitos humanos}

Singular em seus posicionamentos, o filósofo Cornelius Castoriadis, que já foi marxista,parte do pressuposto de que está em construção, ainda que de forma penosa e fragmentária, uma nova sociedade fundada num projeto de autonomia social e individual. Provas nesse sentido poderiam ser encontradas nas revoluções democráticas, nas lutas dos trabalhadores por todo o mundo, no movimento feminista, das minorias culturais, étnicas, regionais.

A instauração dessa sociedade autônoma, por outro lado, haveria de necessariamente importar na destruição de valores hoje tidos como pertinentes e legítimos, na medida em que a ação humana está fundamentalmente voltada no sentido da "maximização antagônica do consumo, do poder, do status e do prestígio"; a técnica, ciência, produção e organização funcionam como fins em si e os indivíduos estão sujeitados a "utilização social eficaz dos móveis essencialmente 'egoístas' em um modo de socialização onde cooperação e comunidade só são consideradas e existem sob o ponto de vista instrumental e utilitário"(CASTORIADIS, 2009, p. 13).

Ao defender uma nova consciência histórica como elemento norteador da transformação social, Castoriadis também aponta no sentido do reconhecimento da verdadeira alteridade nos indivíduos, nos grupos, nas minorias e etnias e, a partir desde reconhecimento não conformativo, organizar uma convivência intersubjetiva verdadeira. Esse processo é inerente e indissociável das escolhas que nos fazem buscar uma sociedade "autônoma e justa", em que indivíduos livres, autônomos, livres e iguais, convivem e se reconhecem reciprocamente. "Reconhecimento que não é simples operação mental - mas também e sobretudo afeto" (CASTORIADIS, 2009, p. 29).

No que diz respeito aos Direitos Humanos, em entrevista publicada no jornal A Folha de São Paulo, em setembro de 1991, Castoriadis fez a seguinte declaração:

“Os direitos do homem já há algum tempo se transformaram numa ideologia que mascara a ausência de um projeto político. Hoje, mais ainda do que na época de Kant, trata-se de um pensamento formal, sem nenhum conteúdo substantivo. Se permanecemos no universalismo jurídico, abstrato, teremos simplesmente uma liberdade negativa, defensiva. Não seria preciso dizer que uma criança que nasce em Uganda não tem hoje os mesmos direitos de uma criança francesa, para mostrar a hipocrisia dos que defendem essa posição." 
Castoriadis elabora seu pensamento a partir de uma relação estreita entre ética e política. Para o autor, se deve considerar que o horizonte sócio-histórico se não estritamente determina os indivíduos, os limita profundamente, num processo que foge ao controle particular. Mas, se por um lado tal constatação se revela quase irredutível, resta incólume a aptidão não somente para questioná-la como também para transformála, possibilitando o surgimento de novas instituições que objetivem a construção da autonomia humana, razão pela qual, esse processo antes de ser ético, é político, estando este sobreposto àquele. De tal modo, quando se questiona o caráter do corpus dos Direitos Humanos como instituição estabelecida, por mais que se faça tendo em conta ensejos éticos, não se pode perder de vista outro sistema, na medida em que operam sobre a instituição global da sociedade, com relevância notória.

Razão pela qual é preciso, antes de tudo, resgatar o sentido do que representa ser um cidadão, um animal político-social, elemento de uma sociedade de pares. Necessário se faz a compreensão segundo a qual a esfera do indivíduo não é separável da esfera política e que para ser senhor de si, para ter liberdade e autonomia e instituições sociais que a garantam e preservem é preciso lutar, continua e ininterruptamente.

O âmbito social-histórico surge então como o locus da validade dos direitos, das instituições e dos comportamentos. Se por um lado o processo histórico de uma sociedade faz surgir questões éticas, por outro, quando o indivíduo é confrontado com eventos que exigem a escolha da melhor ação, também questiona esse conjunto de acepções sociais e implicações de ordem política que instituem a própria sociedade e constituem o indivíduo.

Há que se considerar que Castoriadis não vislumbra a sociedade como a extensão ilimitada das relações intersubjetivas, na medida em que demarca a possibilidade da cooperação se dar somente entre indivíduos já socializados e o fato de que toda sociedade ultrapassa sempre a totalidade dos seus indivíduos (1990, p.114). O autor se refere, consequentemente, à única condição passível de conferir sustentação às relações públicas entre os atores sociais, qual seja, que estes venham a ser considerados no campo dos compromissos recíprocos que constituem uma comunidade e, assim sendo, essa se configura como "exigência política que decorre da existência de uma coletividade de sujeitos que visam a autonomia e querem viver sob as leis que eles mesmos se dão" (CASTORIADIS, 1997, p. 58). 
Nesse sentido, a atividade criativa política ocorre em paralelo à transformação do ethos na medida em que possibilita à uma sociedade ser atilada em relação ao respeito do seu modo de ser como coletividade e de dar-se, a cada vez, uma outra forma de ser, um novo eidos.

Consequentemente, o marco sócio-histórico insurge tal como um plano ontológico particular, determinado pelo processo permanente de criação e do agir humanos e, simultaneamente, como instituidor do próprio humano cuja existência só se revela inserto na sociedade, isso porque cada sujeito reproduz a sociedade em que vive, embora tenha o potencial de modificar constantemente as instituições dessa sociedade ou mesmo criar outras, tendo sempre em conta sua sociedade e atuando em relação a ela, superando-se e recriando-se.

Para Castoriadis (1999, p.104), “o ser é criação. O imaginário e a imaginação são o modo de ser que essa vis formandi do ser em geral toma, nesse rebento do ser/ente total que é a humanidade... Se não fosse isto, o ser seria sempre o mesmo. O ser humano não existiria, a vida não existiria etc.”

Exsurge como ponto fundamental do pensamento de Castoriadis o reconhecimento da dimensão sócio-histórica como um ente auto fundante. No entanto, pensar o socialhistórico como autocriação, como bem adverte o autor, "requer uma conversão ontológica radical" (CASTORIADIS, 1987: 237), ou seja, outra matriz ontológica e epistemológica, uma nova teoria do ser, outra maneira de pensar o ser, não como algo assentado, pronto, oferecido de uma vez por todas.Significa considerar, refletir o ser como fluxo, como rio, como magma, em constante transformação.

Por via de consequência, o processo da construção espaço-temporal do corpus dos Direitos Humanos pode ser considerado como um processo social-histórico. Nesse sentido, importa perceber os direitos humanos, hoje, como um magma de significações. Nesse conjunto de significações em torno dos direitos humanos, tem-se, por suposto, que levar em conta os entendimentos equivocados, distorcidos ou reducionistas, bem como interpretações que são empregadas, muitas ocasiões, sob uma orientação política fruto das relações de poder, naquelas situações nas quais não há de se falar em sujeitos detentores de sua própria autonomia ou da existência de uma autonomia coletiva. 
Sobre a noção de autonomia, tanto individual quanto coletiva, preciosa no pensamento de Castoriadis, considera-se "indivíduo autônomo" o que é capaz de uma atividade refletida própria; que constrói sua autonomia e individualidade pela dedicação outra coisa para além de sua própria existência; aquele que identifica, as leis e o poder da sociedade, como suas próprias leis e como seu próprio poder; que sabe que precisa tomar decisões sobre o que tem que ser feito, sabedor que se vive "sobre o Caos e sobre o Abismo que nós próprios somos Caos e Abismo e que, consequentemente, o domínio é uma ilusão" (2009, p. 51); e se considera como "sociedade autônoma" a que, no marco da reflexividade coletiva (seja pela participação dos cidadãos, de seus questionamentos e decisões coletivas), produz ela mesma as suas próprias leis a serviço de todos os indivíduos, sem exceção.

É precisamente no social-histórico que aparece a questão da validade de direito das instituições e, em consequência, dos comportamentos, sendo, igualmente, a política o afazer lúcido e refletido de questionamento sobre as instituições sociais, aspirando, se imprescindível, transformá-las.

Sendo certo que, nos termos do texto do autor (CASTORIADIS, 1997, p.03):

[...] autonomia política supõe que os homens sejam criadores de suas próprias instituições. Isso exige que ensaiem colocar essas instituições, em conhecimento de causa, lucidamente, logo em uma deliberação coletiva. Isso é o que eu chamo de autonomia coletiva que anda de mãos dadas com a autonomia individual. Uma sociedade autônoma não pode ser formada mais que por indivíduos autônomos. E esses indivíduos autônomos não podem verdadeiramente existir a não ser em uma sociedade autônoma. Por quê? É muito fácil de entender. Um indivíduo autônomo é um indivíduo que não se produz mais do que a partir da reflexão e deliberação. E, assim como não pode produzir-se a não ser desta forma, ele não pode ser um indivíduo democrático, a não ser pertencendo a uma sociedade democrática.

Uma sociedade autônoma exige a existência de indivíduos detentores de autonomia, mas que necessariamente tenham uma visão para além de seus pequenos mundinhos, que reflitam e deliberem tendo em conta o outro como seu semelhante e ao mesmo tempo como ser único e irrepetível participante do mundo.

O projeto proposto por Castoriadis e que, segundo o autor "está nascendo, penosa, fragmentária e contrariamente, já faz dois séculos ou mais, é o projeto de uma nova sociedade, o projeto de autonomia social e individual" (2009, p. 10). Essa nova sociedade já está promovendo uma ruptura com o passado, com a cultura existente e com a criação cultural existente. 
Só será possível uma nova sociedade, em que os direitos de todos os homens e mulheres sejam respeitados, na medida em que seja promovida essa "transformação social radical" que ao mesmo tempo contemple um resgate dos valores da tradição e uma nova postura diante desses mesmos valores, uma articulação distinta entre "esta e as tarefas do presente/futuro", que estão a exigir uma reforma do ser humano, uma reforma da apreensão do mundo pelo ser humano, dessa "rede rígida das significações estabelecidas que nos escondem as coisas e nos esconde a nós mesmos a fluidificação do sentido" (Castoriadis, 2009, p. 81)

\begin{abstract}
Ruptura com a servidão ao passado enquanto passado, ruptura com as inépcias da "tábua rasa"; ruptura com a mitologia do "desenvolvimento", os fantasmas do crescimento orgânico, as ilusões de acumulação aquisitiva. Negações que não são senão a outra face de uma posição; a afirmação da socialidade e da historicidade substantiva como valores de uma sociedade autônoma. Do mesmo modo, temos de reconhecer nos indivíduos, nos grupos, nas etnias, sua verdadeira alteridade (o que não implica que tenhamos de nos conformar, porque seria ainda uma maneira de desconhecê-la ou aboli-la) e organizar a partir deste reconhecimento uma coexistência verdadeira. (CASTORIADIS, 2009, p. 29)
\end{abstract}

A escolha por uma sociedade autônoma e justa, na qual os indivíduos autônomos, sejam livres e iguais e que vivam no reconhecimento recíproco não se dará, segundo o autor, tão somente por conta de uma simples operação mental, mas também e principalmente pelo afeto.

Aqui, Castoriadis, apresenta a necessidade de se reatar os laços rompidos com o passado e se reporta a uma passagem sintomática da Ética a Nicômaco, de Aristóteles que aborda a união das cidades por conta da philia, enquanto que os legisladores se preocupam com a justiça. "Aos philoi, a justiça não é necessária, mas os justos precisam de philia, e a justiça mais alta participa da philia..e o provérbio 'tudo é comum aosphiloi' é correto; porque a philia está na comunhão/comunidade".

Castoriadis (2009, p. 30) esclarece que a philiado Estagirita "não é a amizade dos tradutores e dos moralistas". É o gênero do qual o amor (em todos os sentidos), a afeição, a amizade, etc são espécies. A philia é a ligação entre a afeição e a valorização mútua, que na sociedade política, importa necessariamente liberdade, melhor dizendo, o que se entende por autonomia.

Se por um lado há um processo de dilaceração da humanidade do homem que se deve às instituições que ele mesmo cria, por outro, tal como observa Espinoza no escólio da proposição 18 , da Ética IV, “a razão não pede nada contra a natureza, é, 
portanto, ela mesma que pede que cada um se ame a si mesmo no Tratado Político: “a religião ensina a amar seu próximo com a si mesmo" isso é "a defender o direito do outro como se próprio direito" (TP, cap. I, art. 5).

No contexto de uma sociedade democrática, o amor - aqui entendido como amor a si mesmo e amor ao próximo - e, antes de tudo, uma práxis, um processo de antropogênese, a constituição da ligação social na e pela defesa, exigência e asseveração de um direito que não pode ser desejado pelo indivíduo sem, simultaneamente, ser desejado também para o outro. Esse amor é o mesmo pelo qual o outro defende o meu "direito natural de existir e agir" como se fora seu próprio direito. Um tal amor não se sujeita a nenhum objeto, a nenhum "vestígio de tempo", na medida em que segue em direção "à própria eternidade", nos termos da formulação espinoziana no prefácio do Tratado Teológico-Político (TTP, XX [5] p.p. 236-237).

\section{Por uma metodologia concretizadora do diálogo intercultural dos Direitos Humanos}

Diante da situação de desrespeito aos Direitos Humanos no mundo, na medida em que a diferença, mesmo sendo uma realidade, continuamente tem gerado conflitos, por várias razões, uma releitura do discurso dominante dos Direitos Humanos é imperativa como aposta para um diálogo intercultural que fomente não apenas o contato, mas a compreensão e a aceitação do outro como outro, contribuindo, gradualmente, para a criação de uma sociedade em que as diferentes culturas possam dialogar, já que muitos dos preconceitos advêm do desconhecimento. Por isso, inclusive, a necessidade de reconstrução da normatividade jurídica internacional.

Os diferentes grupos culturais, religiosos, de distintas etnias, que vivem no mesmo território, mas que não entram, necessariamente, em contato uns com os outros formam a denominada sociedade multicultural. Essa é uma sociedade em que a diferença é considerada como uma das principais formas de justificação para a discriminação. Nesse contexto, por exemplo, as minorias podem até ser pacificamente toleradas, mas não são aceitas ou valorizadas. 
No entanto, o que se pretende é que os Direitos Humanos enquanto sistema normativo venha a efetivamente se consubstanciar em elemento possibilitador não somente do diálogo intercultural, mas consagrador do ser humano em sua plenitude, independentemente de qualquer elemento que o distinga ou diferencie, numa sociedade autônoma, nos termos aqui já revelados, pela proposta de Castoriadis.

Assim, a sociedade multicultural poderá se tornar, paulatinamente, uma sociedade que possibilite e garanta o diálogo e o respeito mútuo entre diferentes classes, grupos culturais, nacionais, religiosos, estabelecidos num mesmo território, possam manter relações livres e harmoniosas de interação, troca e reconhecimento mútuo dos seus valores e formas de vida. O corpus dos Direitos Humanos estaria então, a serviço do processo de edificação de relações interpessoais mais igualitárias.

Numa sociedade em que seja fomentado o diálogo entre as diferentes culturas, o indivíduo, por sua natureza um ser gregário e político, para que possa ser um ser capaz de estabelecer pontes de diálogo com o outro, com uma cultura diferente da sua, terá de ser educado, transformado, num ser intercultural. Para tal, há de haver toda uma base normativa que direcione a sociedade nesse sentido. Esta é função precípua dos Direitos Humanos, desde uma concepção inclusiva e plural.

Mas, no sentido de se para repensar e recriar o paradigma contemporâneo da teoria e prática dos Direitos Humanos, qual seria a metodologia capaz de promover uma leitura das múltiplas culturas em termos de Direitos Humanos, para além do discurso dominante, que afaste a exclusão, a ambiguidade, os paradoxos e busque uma tradução que consiga contemplar a superação das diversidades, sob o signo da dignidade humana?

\section{A proposta intermediária moderada de AbdullahiAn-Na'im}

O autor sudanês AbdullahiAn-Na'im (1992, p. 19), busca uma saída intermediária nesse debate partindo do pressuposto liberal da existência de um padrão universal de Direitos Humanos. Procura legitimar a concepção ocidental de Direitos Humanos, a partir da correlação com valores possíveis de reinterpretarão e reconstrução da cultura islâmica. Confere à carência ou escassez de legitimidade cultural interna um dos elementos mais significativos para o seu não reconhecimento. Razão pela qual busca o 
fortalecimento de sua legitimidade no interior das culturas, mediante a luta interna por uma percepção e interpretação esclarecida dos valores e normas culturais, mormente quanto às questões religiosas.

Segundo An-Na'im³ ${ }^{3}$ os padrões universais consagrados nas declarações e tratados internacionais de Direitos Humanos, não necessariamente se ajusta aos valores e instituições de algumas culturas. Assim, esse autor procura legitimar a concepção ocidental de direitos humanos no espectro de valores possíveis de reinterpretarão e reconstrução de sua cultura, a islâmica.

Para tal, expõe a necessidade de se a assentar uma interpretação ocidental dos Direitos Humanos, sem abrir mão dos valores que conformam a tradição islâmica e que, eventualmente, venham a revelar-se com estes incompatíveis.

O autor avalia que a legitimidade cultural do padrão universal de direitos humanos deve ser alcançada tendo em conta um âmbito interno, por meio de discursos culturais internos e, em posteriormente, um âmbito externo, por intermédio de diálogos interculturais.

No que diz respeito ao âmbito interno, An-Na'im (1992, p. 26) defende um aumento da legitimidade cultural interna, através de uma possível reinterpretação e reconstrução axiológica e normativa das instituições tradicionalmente convencionais, pela utilização do que denomina discurso cultural interno, realizado por meio de debates acadêmicos, mobilizações políticas e de manifestações no campo artístico e literário.

Tal movimento traria alternativas mostrando que os valores e instituições tradicionalmente consagrados podem e devem ser revistos e reformulados de acordo com a nova realidade. Assim, se o jurista de hoje trabalhar com as mesmas fontes, pode chegar a uma interpretação moderna dos escritos sagrados. Essa nova interpretação, assim como ocorreu outrora, seria condicionada pela realidade histórica, social, econômica e política atual.

\footnotetext{
${ }^{3}$ Em específico, o autor se refere à cultura islâmica, que vem a ser o campo de seus estudos, e da qual faz parte como muçulmano, na busca de uma moderna hermenêutica na interpretação do Corão.
} 
Em síntese, para o autor é possível a defesa da imutabilidade da Chária islâmica e, em paralelo, defender reformas com interpretação pragmática das diretrizes religiosas ${ }^{4}$. Para tal, considera que o jurista de hoje pode trabalhar com as mesmas fontes, mas utilizar uma hermenêutica moderna e "iluminada" dos textos sagrados. Essa hermenêutica possibilita uma nova interpretação, condicionada pela realidade histórica, econômica e político-social da atualidade. Sendo assim, os textos sagrados ganhariam novas luzes para outra compreensão dos valores e desígnios da Chária, aproximando-a das normas internacionais de Direitos Humanos.

Ao promover-se uma análise da proposta de An-Na'im, é perceptível nas diversas sociedades a ocorrência de percepções e interpretações distintas das posições dominantes e a existência de grupos dispostos a mudá-las. Esses grupos promovem interpretações que que revelam os seus padrões sobre o que é o justo que, por vezes se assemelham ao padrão ocidental liberal de Direitos Humanos. E, por outro lado, demonstram que, potencialmente estariam abertos, ao menos, a outras concepções.

Isso significa que, nos marcos do embate do discurso interno há de haver: primeiro, uma validade objetiva dos argumentos utilizados, à luz dos princípios informadores da cultura, na busca da transformação. E, em segundo lugar, os agentes militantes na luta para a conquista desse espaço argumentativo precisam se membros do próprio grupo, ou seja, membros daquela comunidade. Para An-Na'im (1992, p. 36), se personagens externos, ainda que simpatizantes coerentes com a luta de determinadas culturas incorporarem-se em suas causas, podem torná-lo(a)s vulneráveis à afirmação de que tais simpatizantes seriam, em verdade, agentes vetores de uma cultura externa, que têm por intenção a consolidação dessa cultura alienígena, promovendo um imperialismo cultural. Assim, estariam comprometidos os esforços no sentido da obtenção de legitimidade de valores e normas alternativas, possibilitadores das transformações da referida sociedade.

\footnotetext{
${ }^{4}$ Ainda que se trate de uma minoria de intelectuais muçulmanos, podem ser apontados alguns reformistas islâmicos liberais que defendem o discurso cultural interno, e uma intermediação crítica entre a tradição islâmica e os Direitos Humanos, como é o caso de NoraniOthman, representante da Sisters in Islam da Malásia, uma organização não governamental islâmica de defesa dos direitos das mulheres e o egípcio NasrHamid Abu Zaid, especialista em literatura, que do mesmo modo, busca o significado do Corão de forma contingente, relacionando-o com a realidade histórica atual. (BIELEFELDT, Heiner. Filosofia dos direitos humanos. Tradução de DankwartBernsmüller. São Leopoldo: EditoraUnisinos. 2000,p. 171- 177).
} 
Importante apontar que, para o autor, o discurso cultural interno revela-se tão somente como um passo inicial no sentido da construção da legitimidade cultural do padrão universal dos Direitos Humanos. Ou seja, o discurso cultural interno se materializa como um marco referencial a embasar o diálogo intercultural dos Direitos Humanos, tendo como referência a legitimação da normativa existente a regular os Direitos Humanos. Desde que mantenha sua coerência e substância, estimule a boa-fé, o respeito mútuo e o sentimento de igualdade em relação às demais culturas.

Conforme considera o autor (1992, p. 6):

\begin{abstract}
Em outras palavras, proponho um processo de legitimação retroativa de normas internacionais de direitos humanos existentes, o que implica a possibilidade, ainda que pequena, que as revisões e / ou reformulações podem ser necessários. É precisamente a minha crença pessoal na universalidade dos direitos humanos que me leva a sugerir que devemos buscar para verificar e comprovar a verdadeira universalidade das normas existentes. Este exercício não será credível, no entanto, se não estamos abertos à possibilidade de revisões e / ou reformulações em caso de necessidade. $^{5}$
\end{abstract}

Das considerações que foram tecidas a respeito do pensamento de An-Na'im, é de se perceber que esse autor se propõe a refletir a respeito do paradigma contemporâneo da teoria, prática e efetividade dos Direitos Humanos, nada obstante, sem recomendar a promoção de grandes rupturas. Por assim dizer, conquanto reconheça que a legitimidade cultural do padrão universal liberal dos direitos humanos desde seus primórdios se revele incompleta, o autor parte da existência de uma realidade normativa colocada, ainda que de forma não ilegítima, no sentido do encontro de uma legitimidade local que envolva universalidade dos direitos humanos e os particularismos culturais.

\title{
4. As bases para o diálogo intercultural dos Direitos Humanos em Boaventura de Sousa Santos
}

Há vários grupos de pesquisa que aproximam a questão dos Direitos Humanos do chamado multiculturalismo crítico ou emancipatório e buscam novas formas de sua

\footnotetext{
${ }^{5}$ Conforme o textooriginal : "In other words, I propose a process of retroactive legitimation of existing international human rights standards, which involves the possibility, however slight, that revisions and/or reformulations may be necessary. It is precisely my personal belief in the universality of human rights that leads me to suggest that we must seek to verify and substantiate the genuine universality of the existing standards. This exercise will not be credible, however, if we are not open to the possibility of revisions and/or reformulations should the need arise". (Tradução livre da autora).
} 
tradução ${ }^{6}$. Entre esses grupos, o de Boaventura de Sousa Santos (2010, p. 441-442) é um dos que defendem que

[...]enquanto forem concebidos como direitos humanos universais em abstracto, os direitos humanos tenderão a operar como localismo globalizado e, portanto, como uma forma de globalização hegemônica. Para poderem operar como forma de cosmopolitismo insurgente, como globalização contra-hegemômica, os direitos humanos têm que ser reconceptualizados como interculturais.

A partir desse pressuposto instrumental fundamental, Santos $(2001,2008)$ consegue identificar três fontes de tensões dialéticas que afetam sobremaneira não somente as relações intersubjetivas na modernidade ocidental em todo o seu espectro social, como também a política de Direitos Humanos, desde o final do século passado.

A primeira dentre elas corresponderia à tensão dialética entre o que o autor denomina "regulação social e emancipação social", ou seja, o estabelecimento de limites e o transcender dos limites no sentido dos avanços no campo social. Desde o final do século $\mathrm{XX}$, essa tensão teria perdido o seu potencial criativo, na medida em que "a emancipação deixou de ser o outro da regulação para se tornar no duplo da regulação" (SANTOS, 2001, p.1). Se desde o início do século XX até seus meados as mobilizações emancipatórias foram consequências diretas das crises de regulação e tiveram como resultado o fortalecimento das políticas emancipatórias, nos dias atuais tanto a crise do Estado - seja enquanto regulador ou como Welfare State - como as crises de emancipação social - simbolizadas, para Santos (2001), pela crise da revolução social e do socialismo tomados como padrão da transformação social radical — são simultâneas e alimentam-se uma da outra. De igual sorte, a política dos direitos humanos, que foi ao mesmo tempo uma política reguladora e uma política emancipadora, está enredada nessa crise dúplice, ao mesmo tempo em que é sinal do desejo de ultrapassá-la.

A segunda tensão dialética está situada na relação entre o Estado e a sociedade civil. Segundo Santos, o Estado da modernidade, ainda que se apresente de modo minimalista, é, virtualmente, um Estado maximalista, na medida em que a sociedade civil, configurada como o outro do Estado, se auto-reproduz por meio de leis e regulações originadas do próprio aparelho estatal, e para essas não parecem existir limites, desde que o processo de produção legislativa respeite as regras democráticas

\footnotetext{
${ }^{6}$ Pode ser citado também o grupo francês Droits de l'Homme et Dialogue Interculturel.
} 
colocadas pelo Estado. Aqui também Santos aponta a questão dos direitos humanos como o cerne da tensão:

[...]enquanto a primeira geração de direitos humanos (os direitos cívicos e políticos) foi concebida como uma luta da sociedade civil contra o Estado, considerado como o principal violador potencial dos direitos humanos, a segunda e terceira gerações (direitos econômicos e sociais e direitos culturais, da qualidade de vida, etc) pressupõem que o Estado é o principal garante dos direitos humanos. (Santos:2001, p. 2)

Finalmente, Santos considera que a terceira tensão dialética sobrevém do atrito entre o Estado-nação e o fenômeno designado por globalização. O modelo político praticado na modernidade ocidental é aquele caracterizado por uma unidade básica referencial, os Estados-nação soberanos, que convivem num sistema internacional interestatal, formado por Estados igualmente soberanos. Santos observa, no entanto, que esse sistema interestatal sempre foi idealizado de certo modo anárquico, regulado por uma legalidade muito indelével, e "mesmo o internacionalismo da classe operária sempre foi mais uma aspiração do que uma realidade" (2001, p.3).

Hoje, com a intensificação da globalização que leva a um esgotamento do modelo do Estado-nação, a questão que se coloca é a de perquirir se ambas, regulação social e emancipação social, caminham no sentido dessa mesma escala global. Em que medida esse processo há que se dar e quais os lastros fundamentais a dar sustentação a esse mesmo movimento?

Se, por um lado, já se começa, com toda a evidência, a falar de sociedade civil global, governo global e equidade global e que o baluarte de tal processo é necessariamente o reconhecimento mundial da política dos direitos humanos, por outro vértice tem-se o conflito de um fato que surge como uma provocação ao pensamento. Em suma: tanto as violações dos Direitos Humanos como as lutas em defesa deles continuam a compreender uma decisiva dimensão que não se apresenta ainda supranacional, e, em contrapartida, como bem o aponta Santos (2001), as posições adotadas em relação aos Direitos Humanos seguem sendo produto de ethos específicos. Esses, paulatinamente, demonstram sua incapacidade em construir respostas aos novos desafios postos na busca por definir políticas de reconhecimento na perspectiva de responder ao anseio contemporâneo de democratizar a democracia.

No que pertine à dimensão dos direitos humanos como parte de um projeto cultural, um paradoxo é apresentado pelo autor e reside no fato de "a cultura e especificamente a 
cultura política ocidental é hoje tão indispensável quanto inadequada para compreender e transformar o mundo" (SANTOS, 2010, p.28). Uma crítica profunda desta cultura necessita ter em conta ao mesmo tempo o caráter indispensável dessa cultura e o aspecto basilar de sua inadequação. A tarefa que está posta ao pesquisador é a da realização de uma análise crítico-reflexiva desses elementos a partir de seu interior ou pelo olhar daqueles que em última instância são suas vítimas e que enxergam na modernidade somente violência, exclusão e discriminação.

Não por outro motivo Santos (2010, p. 438-439) considera que, se os Direitos Humanos forem concebidos como universais, mas em abstrato, esses tendem a consubstanciar-se como "localismo globalizado". Portanto, somente sua reconceituação como interculturais é que poderá operar como forma de "cosmopolitismo" não "subalterno", mas "insurgente", ponderando como uma tarefa epistemológica a construção de uma concepção a partir de uma visão intercultural e pós-imperial de Direitos Humanos.

Tais tarefas estão ligadas a proposições que, segundo o autor, podem ser capazes de levar à uma transformação tanto no âmbito da teoria como da eficácia, numa concepção multicultural crítica, portanto intercultural e contra hegemônica de Direitos Humanos, que conformam o denominado "projeto cosmopolita insurgente" (Santos, 2010, p. 445)7 . Estão ligadas às seguintes proposições basilares:

a) a necessidade de superar-se o falso debate entre o universalismo e orelativismo cultural;

b) a comprovação de que, mesmo possuindo concepções de dignidade humana, estas são distintas e, nem todas as culturas a consideram em termos de direitos humanos;

c) o reconhecimento da incompletude das culturas;

d) as distintas concepções de dignidade humana no âmbito das diversas culturas;

e) a constatação da prática pelas diversas culturas de políticas lastreadas nos princípios da igualdade e da diferença.

${ }^{7} \mathrm{O}$ cosmopolitismo insurgente se constitui de reações contra as práticas sócio-econômicas excludentes ou práticas políticas e culturais discriminatórias, mediante o ativismo trans-fronteiriço e o movimento democrático transnacional. 
Sobre a necessidade de se superar a tensão entre o universalismo e orelativismo cultural, o autor aponta a existência de posições polarizadas nesse terreno ora conduzem ao tão repudiado etnocentrismo, ora tomam as diversas realidades culturais como absolutas e incapazes de questionamento. Assim, o debate se revela intrinsecamente falso, na medida em que ambas as posições tendem a inviabilizar os Direitos Humanos enquanto instrumento emancipatório, como pretensamente pretendem.

No contexto dos Direitos Humanos, a posição universalista conduz a um "localismo ocidental globalizado", que se trata do processo pelo qual determinado fenômeno local é globalizado com sucesso. Segue-se o "globalismo localizado", ou seja, o choque especial de práticas e imperativos transnacionais nas condições locais, as quais são, por conta disso, desestruturadas e reestruturadas de modo a responder a esses imperativos transnacionais. Como afirma Santos (2010, p.332), toda tentativa de universalizar ou globalizar valores pressupõe uma procedência local, porque os valores sociais e culturais dependem do contexto de sua enunciação. $O$ fenômeno da globalização demonstra o pressuposto da localização. Daí a afirmação, já apontada na primeira parte deste trabalho por Mutua (2008), de que os valores "universais" consagrados nas declarações e tratados internacionais de Direitos Humanos e a concepção de dignidade humana por eles defendida possuem uma feição cultural específica: a tradição ocidental eurocêntrica.

Contra isso, há de haver a preocupação dialógica intercultural isomórfica, ou seja, ainda que com linguagens distintas são procurados pontos de convergência intercultural ${ }^{8}$.

Em sentido oposto e, do mesmo modo, incapaz de conceber o consenso, está situada a posição relativista, na medida em que não considera a possibilidade da construção de uma compreensão cultural mútua. Isso porque, para os relativistas, toda e qualquer tentativa nesse sentido significaria a imposição de uma cultura sobre a outra.

Se por outro lado, é possível considerar que a noção de relatividade dos aspectos culturais é fundamental para o diálogo, na medida em que leva as referentes culturas a reconhecerem a validade dos valores alheios, de outro vértice, "há que se desenvolver

\footnotetext{
${ }^{8}$ A noção de interculturalidade para além do encontro entre maiorias e minorias, ou do simples contato inter-étnico. A interculturalidade se revela como uma perspectiva e uma postura que acolhem e adotam o caráter intercultural de cada uma das culturas, sem uma pretensão de igualdade entre ambas.
} 
critérios que permitam distinguir uma política progressista de uma política conservadora de direitos humanos" (SANTOS, 2010, p. 445).

Na expectativa da construção de uma concepção normativa de Direitos Humanos que efetivamente contemple e tenha efetividade nas diferentes culturas, Sousa Santos propõe a superação tanto do universalismo quanto o relativismo por meio da utilização de diálogos interculturais que foquem as questões convergentes, isomórficas, ou seja, aquelas questões que, apesar de provenientes de universos de sentido distintos, consigam convergir numa unidade valorativa. Isso é possível na medida em que distintas culturas apresentam sentidos, significados, conceitos próprios e específicos para preocupações comuns.

Como maximizar a interculturalidade sem subscrever o relativismo cultural e epistemológico [...] É no campo deste desafio que a verificação da inadequação ou incompletude dos conceitos de cultura política ocidental deve servir de impulso à busca de conceitos alternativos oriundos de outras culturas e à promoção de diálogos entre eles, diálogos que tenho designado por hermenêutica diatópica, e que poderão conduzir a universalismos regionais ou setoriais construídos a partir de baixo, ou seja, a esferas públicas globais contra-hegemônicas a que também chamo cosmopolitismo subalterno insurgente.(SANTOS, 2010, p. 43) (Negrito nosso)

O diálogo intercultural sobre os Direitos Humanos para a superação dos problemas relacionados à concepção universalista, para Santos (2010, p. 445) teria como eixo condutor a dignidade humana, preservando no que fosse possível, as valorações de cada posição, visando o estabelecimento de valores ou exigências máximas de dignidade, ao invés de valores mínimos, o chamado “denominador comum”.

Contra o relativismo cultural, por inverso, o processo necessita ter em conta os critérios indicadores das políticas culturais internas que permitem o progresso da dignidade humana, de modo a distingui-las das políticas conservadoras, que, em geral, fornecem os subsídios às políticas autoritárias e de exclusão. Assim, há que se desenvolver aqueles critérios que possibilitem o reconhecimento e a distinção daquelas políticas consideradas progressistas que devem ser tidas como válidas e estimuladas por todas as culturas das políticas conservadoras que não merecem prosperar.

A questão que se coloca vai no sentido de se estabelecer quem terá a legitimidade para a tarefa e quais os limites da tolerância.

No que diz respeito à segunda proposição, segundo a qual, a comprovação de que, mesmo possuindo concepções de dignidade humana, estas são distintas e, nem todas as 
culturas a apreciam em termos de direitos humanos, considera que é de fundamental importância que sejam identificadas as "preocupações isomórficas", a saber, que os marcos do diálogo proposto por uma cultura devem ser o reflexo de preocupações que localizem sua correspondência na cultura com a qual dialogue, a partir da identificação de designações ou conceitos que, apesar de diferentes, "podem transmitir preocupações ou aspirações semelhantes ou mutuamente inteligíveis" Santos $\left(2010\right.$, p. 446) ${ }^{10}$.

A terceira proposição guarda relação com o fato de que as diversas concepções culturais de dignidade humana existentes se revelam incompletas, muito embora essa percepção não seja totalmente percebida no interior da cultura, sendo somente perceptível a partir da perspectiva externa. Essa incompletude seria uma característica inerente à existência de uma pluralidade de universos culturais.

No entanto, o que acontece é um sentimento de completude que provoca o afastamento entre culturas, de sorte que existe a necessidade do aumento dessa percepção de incompletude cultural como condição inicial para que seja possível uma “concepção emancipadora e multicultural de direitos humanos" (SANTOS, 2010, p. 446), com a utilização do diálogo intercultural e o uso da hermenêutica diatópica, para que as culturas possam refletir criticamente sobre suas próprias construções culturais e a reconhecer as construções alheias, sem que isso signifique nem submissão nem desestruturação ou dominação cultural.

Não se pode deixar de apontar que o reconhecimento da incompletude das culturas pode vir a se deparar com, pelo menos, duas questões que exigem cautela: primeiro, nada obsta que uma cultura se considere completa e não tenha interesse em dialogar com as demais; segundo, pode ocorrer que determinada cultura que acolha a incompletude que outras culturas lhe conferem e aceita participar dos diálogos

\footnotetext{
${ }^{9}$ No Dicionário Aurélio Século XXI, isomorfismo significa:"1. Álg. Mod. Correspondência biunívoca entre os elementos de dois grupos que preserva as operações de ambos. 2. Quím. Fenômeno apresentado por substâncias diferentes que cristalizam no mesmo sistema com a mesma disposição e orientação dos átomos, das moléculas ou dos íons". Já a palavra morfismo quer dizer a "aplicação de um conjunto sobre outro, que preserva as operações definidas em ambos" (FERREIRA, Aurélio Buarque de Holanda. Novo aurélio século XXI. Rio de Janeiro: Nova Fronteira, 1999, p. 1143 e 1367).

${ }^{10}$ A esse respeito e no mesmo sentido, Panikkar $(1984$, p. 29) faz uso de expressão por ele cunhada quando se refere à busca pelo "equivalente homeomórfico", e, explicita que o "Homeomorfismo não é o mesmo que analogia; ele representa uma equivalência funcional peculiar descoberto através de uma transformação topológica. É uma espécie de analogia funcional existencial ". Do original: "Homeomorphismisnotthesame as analogy; it represents a peculiar functionalequivalencediscoveredthrough a topologicaltransformation. It is a kind of existential functional analogy" (Traduçãolivre da autora).
} 
interculturais, corre o risco de sujeitar-se à conquista cultural, seja pela absorção, ou desestruturação ou destruição.

Na medida em que a estratégia do fechamento cultural objetivamente impede toda e qualquer tentativa de busca do diálogo, segundo Santos (2010, p. 447) deve-se optar pela consciência da incompletude e pelo diálogo, mas unicamente se não representar uma conquista cultural - o que, como exposto, paradoxalmente aniquilaria a própria noção de diálogo.

A quarta proposição envolve as distintas concepções de dignidade humana no âmbito das diversas culturas, demonstrando que nenhuma cultura se configura como um todo rígido, homogêneo, impenetrável, ou seja, as culturas tendem a se organizar com base a diferentes concepções de dignidade humana, algumas mais amplas, outras mais estreitas.

Um bom exemplo disso se encontra nas concepções e práticas profundamente distintas relativas aos Direitos Humanos que se encontra na modernidade ocidental, na medida em que convivem, por um lado as concepções liberal e social-democrática, cujas prioridades se revelam absolutamente distintas, a saber: aos primeiros, os direitos civis e políticos, enquanto para os outros, os direitos sociais e econômicos. A questão se coloca em estabelecer qual delas "propõe um círculo de reciprocidade mais amplo" (SANTOS, 2010, p. 446).

Por último, a quinta proposição parte da constatação da prática pelas diversas culturas de políticas lastreadas nos princípios da igualdade e da diferença. Assim, percebe-se que as culturas costumam tomar por base dois princípios de natureza hierárquica - a igualdade e a diferença. De tal modo, que as pessoas são normalmente separadas por critérios que apartam os iguais, de um lado, e diferentes, do outro, sem que haja necessariamente uma sobreposição desses princípios.

Para o autor, há que se saber distinguir as lutas que envolvem políticas de igualdade e de reconhecimento igualitário das diferenças, a fim de alcançar uma política emancipatória de direitos humanos, na medida em que "nem todas as igualdades são idênticas e nem todas as diferenças são desiguais" (SANTOS, 2010, p. 447).

São esses os preceitos necessários à promoção de um diálogo intercultural que envolva a normativa própria dos Direitos Humanos, sob o signo da dignidade humana, 
que ao invés de se valer de "falsos universalismos", consegue construir-se a partir de uma "constelação de sentidos locais", como uma rede de referências normativas capacitantes e inclusivas, como um ponto de partida coerente para a busca da troca entre os diferentes saberes. (SANTOS, 2010, p. 447).

Por outro lado, o autor enfatiza a necessidade da maximização da interculturalidade, sempre com a preocupação de correr-se o risco de descambar em um relativismo cultural e epistemológico. Nisso reside a importância do trabalho de tradução defendido por Santos, tendo como referencial uma hermenêutica diatópica, nos moldes da elaboração de Panikkar

É no campo deste desafio que a verificação da inadequação ou incompletude dos conceitos da cultura política ocidental deve servir de impulso à busca de conceitos alternativos oriundos de outras culturas e à promoção de diálogos entre eles, diálogos que tenho designado por hermenêutica diatópica, e que poderão conduzir a universalismos regionais ou setoriais construídos a partir de baixo, ou seja, a esferas públicas globais contra-hegemônicas a que também chamo cosmopolitismo subalterno ou insurgente. (SANTOS, 2010, p. 43).

A proposta do autor vai no sentido de um trabalho de tradução cuja proposta é a da transformação do desmedido em diferença, mas uma diferença que possibilite a inteligibilidade mútua dos distintos projetos de emancipação social, mas que não importe nem na dependência nem no absorvimento de um pelo outro ou por qualquer outro.

Finalmente, é importante esclarecer que Sousa Santos e An-na'im possuem concepções divergentes no que diz respeito ao fórum privilegiado a ser empregado na realização do diálogo intercultural na procura de novos consensos que possibilitem distintos olhares a respeito dos aspectos normativos e materiais dos direitos humanos.

Para An-na'im, a expressão intracultural como fórum hábil para a produção de consensos teria mais legitimidade e eficácia enquanto tal. Assim, para esse autor, a utilização do Direito Internacional dos Direitos Humanos é vista comoreal estimuladora das transformações culturais. É frequente na literatura (BIELFELT, 2000)encontrar-se criticas desse cariz ao autor pelo seu uso pueril ou arrebatado do padrão internacional dos direitos humanos, o que evidenciaria que, para An-na'im, a tradição ocidental teria maior relevância para a definição e concretização dos direitos humanos. Não obstante, segundo o autor,essa tradição ocidental dos direitos humanos teria sido enriquecida com contribuições do mundo islâmico, e a conformação dos Estados nacionais, conquanto 
expandida pelo processo de colonização não seria capaz de imprimir tão profundamente as culturas locais.

\section{Considerações finais}

Da reflexão anteriormente desenvolvida é possível inferir que se tem acolhido o pressuposto segundo o qual formular direitos humanos com pretensão universal a partir de valores que consideram apenas uma parcela da humanidade não é uma postura apropriada. A rigor, não se deve considerar uma determinada cultura ou determinadas contribuições culturais como superior às demais.

Qualquer concepção que leve em conta os direitos humanos como universais requer uma construção fundada em um diálogo intercultural em que cada uma das partes interlocutoras esteja previamente disposta a se deixar influenciar pela outra(s), como condição sinequa non para a construção de um consenso em torno de valores comuns que possam ser tutelados.

Após a formação de tal consenso que subsume valores a serem protegidos como direito de todo ser humano, em condições politicamente equânimes, que viva em qualquer lugar do planeta, é necessária a construção e manutenção de um sistema protetivo dotado de força coercitiva, capaz de sancionar todos os potenciais violadores desses direitos. Sem essa tutela efetiva, independentemente de sua forma de construção, o referido corpus de direitos humanos prosseguirá como um mero conjunto formal de normas que se limitam a funcionar como figuras de aconselhamento, sem efetividade.

Do contrário, os direitos humanos, ainda que fruto do consenso universal, continuarão a ser desprovidos da força necessária para se imporem em face de violações que emergem, não raro de modo irrefreável, em nossos tempos sombrios.

\section{REFERÊNCIAS}

AN-NA 'IM, Abdullahi Ahmed. Toward a cross-cultural approach to defining international standards of human rights: the meaning of cruel, inhuman, or degrading treatment or punishment. In: AN-NA 'IM, Abdullahi Ahmed (Ed.). Human rights in cross-cultural perspectives. Philadelphia: University of Pennsylvania Press, 1992, p. $19-43$. 
AN-NA 'IM, Abdullahi Ahmed e HAMMOND Jeffrey. Cultural Transfomation and Human Rights in African Societies, in Cultural Transfomation and Human Rights in Africa, Zed Books Ltd.: London, 2002.

CASTORIADIS, Cornelius. A instituição imaginária da sociedade. Tradução de Guy Reynaud. 2. ed. Rio de Janeiro: Paz e Terra, 1982.

CASTORIADIS, C. As Encruzilhadas do Labirinto. Tradução por Carmen Sylvia Guedes e Rosa Maria Boaventura. Rio, Paz e Terra, [1978].1987. vol.I 535p.

CASTORIADIS. Cornelius. Entrevista aFernando de Barros e Silva. Publicado na Folha de S.Paulo, sábado, 7 de setembro de 1991. Disponível em: 〈http://almanaque.folha.uol.com.br/entcastoriades.htm〉. Acesso em:06 jan. 2016.

CASTORIADIS. Cornelius. Le monde morcelé: lesCarrefoursdulabyrinthe III, deuxièmeédition. Paris: Seuil, 1990.

CASTORIADIS, Cornelius. Da autonomia em política: "O indivíduo privatizado". Disponível em: 〈http://pt.slideshare.net/LuizrodriguesRodrigues/cornelius-castoriadisda-autonomia-em-poltica-o-individuo-privatizado». Acesso em: 06 jan. 2016.

CASTORIADIS, Cornelius. Janela sobre o Caos, SP:Ideias\&Letras, 2009.

PANIKKAR. Myth, Faith, and Hermeneutics: Cross-Cultural Studies Hardcover January, 1980.

PANIKKAR. Is the notion of human rights a western concern?, in Interculture, 27 (1), Cahier 82, p. 28-47, 2002.

PANIKKAR, Raimundo. Paz e Interculturalidad: una reflexión filosófica. Barcelona: Herder, 2006.

PANIKKAR. Seria a noção de direitos humanos um conceito universal? In: BALDI, César Augusto (Org.). Direitos Humanos na Sociedade Cosmopolita. Rio de Janeiro: Renovar, 2004. p. 205-238.

SANTOS, Boaventura de Sousa. Se Deus fosse um activista dos Direitos Humanos, Coimbra: Almedina, 2013. 
Modernidade. São Paulo, Cortez, 1995.

. Para além do Pensamento Abissal: Das linhas globais a uma ecologia de saberes. In: Revista Crítica de Ciências Sociais, 78, Outubro 2007: p. 3-46.

O discurso e o poder: ensaio sobre a sociologia da retórica juridical. Porto Alegre: Sérgio Antonio Sérgio Antonio Fabris, 1988. Por uma concepção multicultural de direitos humanos. In: SANTOS, Boaventura de Sousa. (Org). Reconhecer para libertar: os caminhos do cosmopolitismo cultural. Rio de Janeiro: Civilização Brasileira, 2003, p. 429-461.

.A gramática do tempo: por uma nova cultura política, $3^{\text {a }}$. Ed., $1^{\text {a }}$. Reimpressão, São Paulo: Cortez, 2010.

Submetido em: 10/07/2018

Aceito em : 30/07/2018 